\title{
Enhanced left ventricular mass regression after aortic valve replacement in patients with aortic stenosis is associated with improved long-term survival
}

\author{
Ayyaz Ali, MRCS, Amit Patel, MBBS, Ziad Ali, MRCS, MRCP, PhD, Yasir Abu-Omar, MRCS,
} Amber Saeed, MD, Thanos Athanasiou, PhD, FETCS, and John Pepper, FRCS

\begin{abstract}
Background: Aortic valve replacement in patients with aortic stenosis is usually followed by regression of left ventricular hypertrophy. More complete resolution of left ventricular hypertrophy is suggested to be associated with superior clinical outcomes; however, its translational impact on long-term survival after aortic valve replacement has not been investigated.
\end{abstract}

\begin{abstract}
Methods: Demographic, operative, and clinical data were obtained retrospectively through case note review. Transthoracic echocardiography was used to measure left ventricular mass preoperatively and at annual follow-up visits. Patients were classified according to their reduction in left ventricular mass at 1 year after the operation: group 1, less than $25 \mathrm{~g}$; group 2, 25 to $150 \mathrm{~g}$; and group 3, more than $150 \mathrm{~g}$. Kaplan-Meier and multivariable Cox regression were used.
\end{abstract}

Results: A total of 147 patients were discharged from the hospital after aortic valve replacement for aortic stenosis between 1991 and 2001. Preoperative left ventricular mass was $279 \pm 98 \mathrm{~g}$ in group $1(\mathrm{n}=47), 347 \pm 104 \mathrm{~g}$ in group $2(\mathrm{n}=62)$, and $491 \pm 183 \mathrm{~g}$ in group $3(\mathrm{n}=38)(P<.001)$. Mean time to last echocardiogram was $6.2 \pm 3.2$ years. Left ventricular mass at late follow-up was $310 \pm 119 \mathrm{~g}$ in group $1,267 \pm 107 \mathrm{~g}$ in group 2 , and $259 \pm 96 \mathrm{~g}$ in group $3(P=.05)$. Transvalvular gradients at follow-up were not significantly different among the groups (group 1,24.8 \pm $23 \mathrm{~mm} \mathrm{Hg}$; group 2, $21.4 \pm 16 \mathrm{~mm} \mathrm{Hg}$; group 3, $14.7 \pm 9 \mathrm{~mm} \mathrm{Hg})(P=.31)$. There was no difference in the prevalence of other factors influencing left ventricular mass regression such as ischemic heart disease or hypertension, valve type, or valve size used. Ten-year actuarial survival was not statistically different in patients with enhanced left ventricular mass regression when compared with the log-rank test (group 1, 51\% $\pm 9 \%$; group 2, 54\% $\pm 8 \%$; and group $3,72 \% \pm 10 \%)(P=.26)$. After adjustment, left ventricular mass reduction of more than $150 \mathrm{~g}$ was demonstrated as an independent predictor of improved long-term survival on multivariate analysis $(P=.02)$.

Conclusions: Our study is the first to suggest that enhanced postoperative left ventricular mass regression, specifically in patients undergoing aortic valve replacement for aortic stenosis, may be associated with improved long-term survival. In view of these findings, strategies purported to be associated with superior left ventricular mass regression should be considered when undertaking aortic valve replacement. (J Thorac Cardiovasc Surg 2011;142:285-91)

Aortic valve stenosis (AS) subjects the left ventricle to abnormal loading conditions leading to the development of left ventricular hypertrophy $(\mathrm{LVH}){ }^{1}$ A principal aim of the surgical treatment of aortic valve lesions is to restore normal left ventricular (LV) hemodynamics. ${ }^{2}$ Aortic valve replacement (AVR) is usually followed by regression of LVH., This is considered to be advantageous and potentially to be associated with improved clinical outcomes. ${ }^{5}$ However, the

\footnotetext{
From the Department of Cardiothoracic Surgery, Royal Brompton Hospital, London, United Kingdom.

Disclosures: Authors have nothing to disclose with regard to commercial support.

Received for publication Aug 9, 2009; revisions received July 29, 2010; accepted for publication Aug 31, 2010; available ahead of print Jan 27, 2011.

Address for reprints: Ayyaz Ali, MRCS, Department of Cardiothoracic Surgery, Royal Brompton Hospital, London, SW3 3NP, United Kingdom (E-mail: ayyaz75@gmail.com).

$0022-5223 / \$ 36.00$

Copyright (C) 2011 Published by Elsevier Inc. on behalf of The American Association for Thoracic Surgery

doi:10.1016/j.jtcvs.2010.08.084
}

presumed correlation between left ventricular mass (LVM) regression and impaired long-term outcome is based on extrapolation from historical studies, which documented the negative impact of LVH on survival in patients with hypertensive heart disease. ${ }^{6-9}$ Ventricular hypertrophy secondary to aortic valve disease is a distinct entity from that which occurs in response to essential hypertension. ${ }^{10}$ Consequently, presumptions that hypertrophy in these 2 settings will have an equivalent effect on outcome are unfounded. The impact of persistent LVH on long-term clinical outcomes, specifically in a population of patients who have undergone AVR for significant AS, has not been previously investigated. Our aim was to evaluate whether enhanced LVM regression after AVR is correlated with improved long-term survival.

\section{METHODS}

This is a retrospective review of a consecutive series of patients who underwent AVR with a stentless bioprosthesis for aortic valve disease 


\section{Abbreviations and Acronyms \\ AS = aortic valve stenosis \\ $\mathrm{AVR}=$ aortic valve replacement \\ $\mathrm{LV}=$ left ventricular \\ LVH $=$ left ventricular hypertrophy \\ $\mathrm{LVM}=$ left ventricular mass}

from January 1991 to January 2001. Patients were not excluded from analysis if they had additional concomitant cardiac procedures.

\section{Bioprosthetic Stentless AVR}

The Toronto Stentless Porcine Valve (St Jude Medical, Inc, St Paul, Minn) was the stentless valve used in this series. Allograft valves were also used. An established allograft cryopreservation protocol has been in place at our institution for over 15 years.

\section{Surgical Technique}

Operations were performed by a single surgeon (J.P.) The decision to use a biological valve and type of valve selected was left to surgeon-patient preference. In general, allografts were used for redo procedures and in patients of younger age. All procedures were performed with the patient supported by cardiopulmonary bypass with cooling to $28^{\circ} \mathrm{C}$. Myocardial protection was undertaken with antegrade and retrograde cold blood cardioplegia. The majority of bioprostheses were implanted in the subcoronary position. With allograft valves, the coronary sinuses were excised but the noncoronary sinus was preserved. The valve was then implanted with separate inflow and outflow suture lines. Interrupted sutures were used for the proximal suture line and continuous for the distal anastomosis. Separate mattress sutures were used to secure the commissures. Allograft valves were also implanted as a free-standing root replacement with reimplantation of the native coronary artery ostia as buttons within the allograft wall.

\section{Data Acquisition}

Demographic, clinical, and operative data were obtained from individual patient hospital records. Our follow-up protocol included annual echocardiograms to assess cardiac and allograft valve function. Serial echocardiographic reports were reviewed to document LVM. Mortality was determined using the NHS strategic tracing system (NHS, United Kingdom) and survivors were contacted by telephone for interview. Approval for this study was obtained from Royal Brompton and Harefield and Imperial College Ethics Committee (Ethics number 00-128).

\section{Echocardiographic Details}

Patients in our series had annual echocardiographic follow-up at our institution. Transthoracic echocardiography was performed with the Hewlett-Packard Sonos 5000 echocardiograph (Hewlett-Packard, Houston, Tex). Two-dimensional images were obtained with standard apical 5chamber, parasternal short- and long-axis views. Continuous wave Doppler was used to measure transvalvular gradients. LVM was measured by 2 experienced echocardiographers in all patients before and after AVR. LV volumes in cubic centimeters were measured from apical 4-chamber views using the Simpson rule. In patients in whom the Simpson rule could not be used, the area-length method was used. LVM was then calculated using values obtained for the external (EDVe) and internal (EDVi) end-diastolic volume using the following equation: $\mathrm{LVM}=1.05(\mathrm{EDV}-\mathrm{EDVi}) \mathrm{g}$.

\section{Clinical Definitions and Follow-up Protocol}

Hypertension was defined as a systolic blood pressure greater than $140 \mathrm{~mm} \mathrm{Hg}$ or a diastolic blood pressure greater than $90 \mathrm{~mm} \mathrm{Hg}$. Poor
LV function was defined as an LV ejection fraction of less than or equal to $30 \%$, documented on either left ventriculography or transthoracic echocardiography. The end points of interest were the following: postoperative change in LVM at 1 year of follow-up and actuarial freedom from death. Clinical follow-up data were collected in the immediate postoperative period and subsequently during annual clinic visits. All surviving patients remained on this annual surveillance protocol. The survival commenced at the time of first year and ended at the time of death-event or at last follow-up (censoring). The selection of the time point of 1 year postoperatively was considered as being more clinically important in informing us about patient prognosis. All patients were included on an intentionto-treat basis; thus all attempted procedures, including initial technical procedure failures, were included in the overall analysis.

\section{Statistical Methods}

Patients were classified according to their reduction in LVM at 1 year of follow-up: group 1, less than $25 \mathrm{~g}$ or increase in LVM from baseline; group 2, 25 to $150 \mathrm{~g}$; group 3, more than $150 \mathrm{~g}$. Data were expressed as mean \pm standard deviation for normally distributed values and median \pm interquartile change when variables were not normally distributed. Normal distribution of each continuous variable was assessed with the Kolmogorov-Smirnov test, and for comparison, analysis of covariance with Bonferroni correction for normally distributed variables was used. For the nonnormally distributed variables, the Kruskal-Wallis test was used to compare groups, and the cutoff value for significance was adjusted for multiple comparison to the value of .01. Categorical variables were shown as percentages. Comparisons for categorical variables were performed with the $\chi^{2}$ test.

Actuarial outcomes were compared with Kaplan-Meier curves and multivariable Cox proportional hazards regression. A log-rank test was used to determine whether significant differences existed between curves. The proportional hazard assumption was tested for each covariate by 2 methods: first, correlating the corresponding Scaled Schoenfeld Residuals with the rank of time; second, using the procedure "stphtest" in Stata (Stata Corporation, College Station, Tex). The linearity assumption for each binary covariate was assessed graphically with Martingale residuals. To elucidate associated causative factors to the outcomes of interest, we performed a multivariable regression analysis. Initially, univariable regression analysis was used to determine all significant confounding variables (covariates). Those associated confounding variables were subsequently included in the multivariable regression model. Statistically $(P \leq 0.2)$ or clinically significant causative factors from the univariable analysis were adjusted for (included) in the multivariable model. We also included those variables that were found to have a different distribution among the 3 LVM regression groups and we thought may have been able to influence results. All statistical tests were 2-sided. In all cases, corrections were not made for multiple comparisons. Statistical analysis was performed using SPSS 17.0 (SPSS Inc, Chicago, Ill) and Stata 9.0 (Stata Corporation).

\section{RESULTS}

Between January 1, 1991, and January 1, 2001, 153 patients underwent AVR with a homograft or stentless porcine valve. There were $6(3.9 \%)$ postoperative deaths. One hundred forty-seven patients who survived AVR underwent postoperative echocardiography at 1 year to assess the extent of LVM regression. Forty-seven patients had less than $25 \mathrm{~g}$ of LVM regression at late follow-up (group 1), in 62 patients LVM regression was between 25 and $150 \mathrm{~g}$ (group 2 ), and in 38 patients LVM regression was greater than 150 g. Patient characteristics according to extent of LVM regression are listed in Table 1. 
TABLE 1. Baseline characteristics

\begin{tabular}{|c|c|c|c|c|}
\hline $\begin{array}{l}\text { Degree of LVM } \\
\text { regression }\end{array}$ & $\begin{array}{l}\text { Group 1: } \\
\quad<25 \mathrm{~g}\end{array}$ & $\begin{array}{l}\text { Group 2: } \\
25-150 \mathrm{~g}\end{array}$ & $\begin{array}{l}\text { Group 3: } \\
>150 \mathrm{~g}\end{array}$ & $\begin{array}{c}P \\
\text { value }\end{array}$ \\
\hline No. & $47(32)$ & $62(42)$ & $38(26)$ & \\
\hline Age $\geq 70 y$ & $21(45)$ & $28(45)$ & $15(40)$ & .84 \\
\hline Female sex, n $(\%)$ & $15(32)$ & $18(29)$ & $12(32)$ & .92 \\
\hline $\begin{array}{l}\text { Hypercholesterolemia, } \\
\text { n }(\%)\end{array}$ & $10(21)$ & $8(13)$ & $6(16)$ & .51 \\
\hline Diabetes, n (\%) & $5(11)$ & $3(5)$ & $2(5)$ & .45 \\
\hline Hypertension, n (\%) & $17(36)$ & $24(39)$ & $15(41)$ & .92 \\
\hline $\begin{array}{l}\text { Serum creatinine } \\
\quad \geq 150 \mu \mathrm{mol} / \mathrm{L}\end{array}$ & $2(4)$ & $0(0)$ & $3(8)$ & .09 \\
\hline $\begin{array}{l}\text { Antihypertensive } \\
\text { treatment (ACE } \\
\text { inhibitor) }\end{array}$ & $15(32)$ & $22(37)$ & $14(39)$ & .77 \\
\hline Sinus rhythm & $40(85)$ & $56(90)$ & $32(84)$ & .60 \\
\hline Valve size $\geq 25 \mathrm{~mm}$ & $22(47)$ & $31(50)$ & $19(50)$ & .94 \\
\hline Redo AVR & $5(11)$ & $4(7)$ & $3(8)$ & .73 \\
\hline \multicolumn{5}{|l|}{ Operative urgency } \\
\hline Emergency, n (\%) & $6(13)$ & $5(8)$ & $3(8)$ & .66 \\
\hline \multicolumn{5}{|l|}{ LV function } \\
\hline $\mathrm{LVEF} \leq 30 \%, \mathrm{n}(\%)$ & $7(15)$ & $7(11)$ & $3(2)$ & .60 \\
\hline \multicolumn{5}{|l|}{$\begin{array}{l}\text { Preoperative functional } \\
\text { status }\end{array}$} \\
\hline $\begin{array}{l}\text { Pre NYHA class III/IV, } \\
\text { n }(\%)\end{array}$ & $27(57)$ & $31(50)$ & $20(53)$ & .74 \\
\hline \multicolumn{5}{|l|}{ Preop echocardiography } \\
\hline LVEDD, cm (SD) & $4.8(0.97)$ & $5.3(0.87)$ & $5.8(1.1)$ & $<.001$ \\
\hline LVESD, cm (SD) & $3.3(1.1)$ & $3.5(0.90)$ & $3.76(0.88)$ & .10 \\
\hline LVEF, \% (SD) & $65(18)$ & $69(15)$ & $70(13)$ & .24 \\
\hline $\begin{array}{l}\text { Transaortic gradient, } \\
\text { mm Hg (SD) }\end{array}$ & $69(24)$ & $74(21)$ & $71(13)$ & .54 \\
\hline LVM, g (SD) & $279(98)$ & 347 (104) & $491(183)$ & $<.00$ \\
\hline
\end{tabular}

$L V M$, Left ventricular mass; $A C E$, angiotensin-converting enzyme; $A V R$, aortic valve replacement; $L V$, left ventricular; $L V E F$, left ventricular ejection fraction; $N Y H A$, New York Heart Association; $L V E D D$, left ventricular end-diastolic dimension; $S D$, standard deviation; $L V E S D$, left ventricular end-systolic dimension.

\section{Baseline Characteristics}

The mean age of our study population was $65 \pm 12$ years, consisting of $102(70 \%)$ men. There were no differences between groups with regard to age or sex. Seventy-eight $(53 \%)$ patients were in New York Heart Association functional class III/IV preoperatively. In total, 147 patients were operated on for aortic stenosis. Fourteen $(10 \%)$ patients underwent emergency surgery. Twelve $(8 \%)$ patients in the series were undergoing redo AVR.

\section{Preoperative Echocardiography}

Details relating to preoperative echocardiographic measurements are listed in Table 1. Patients in group 3 had significantly larger LV end-diastolic diameter $(P<.001)$. There was no difference between groups in end-systolic dimensions, LV ejection fraction, or preoperative transvalvular gradient. LVM was also significantly higher in group 3 patients at baseline $(P<.001)$.
TABLE 2. Operative characteristics and postoperative outcomes

\begin{tabular}{|c|c|c|c|c|}
\hline $\begin{array}{l}\text { Degree of LVM } \\
\text { regression }\end{array}$ & $\begin{array}{l}\text { Group 1: } \\
\quad<25 \mathrm{~g}\end{array}$ & $\begin{array}{l}\text { Group 2: } \\
\text { 25-150 g }\end{array}$ & $\begin{array}{l}\text { Group 3: } \\
>150 \mathrm{~g}\end{array}$ & $\begin{array}{c}P \\
\text { value }\end{array}$ \\
\hline No. & $47(32)$ & $62(42)$ & $38(26)$ & \\
\hline $\begin{array}{l}\text { Concomitant CABG, } \\
\mathrm{n}(\%)\end{array}$ & $18(38)$ & $19(31)$ & 7 (19) & .16 \\
\hline No. of grafts, $n$ (SD) & $0.53(0.8)$ & $0.53(0.9)$ & $0.35(0.8)$ & .56 \\
\hline \multicolumn{5}{|l|}{ Valve type and insertion } \\
\hline Homograft, $\mathrm{n}(\%)$ & $22(47)$ & $28(45)$ & $17(45)$ & .98 \\
\hline Valve size, $\mathrm{mm}(\mathrm{SD})$ & $24.5(2.6)$ & $24.5(2.2)$ & $24.8(2.7)$ & .75 \\
\hline $\begin{array}{l}\text { Subcoronary implant, } \\
\text { n (\%) }\end{array}$ & $42(89)$ & $56(90)$ & $32(84)$ & .63 \\
\hline \multicolumn{5}{|l|}{$\begin{array}{l}\text { Postoperative functional } \\
\text { status }\end{array}$} \\
\hline $\begin{array}{l}\text { Postop NYHA class } \\
\text { III/IV, n (\%) }\end{array}$ & $3(6)$ & $0(0)$ & $1(3)$ & .13 \\
\hline $\begin{array}{r}\text { Postoperative } \\
\text { pacemaker }\end{array}$ & $1(2)$ & $2(3)$ & $8(22)$ & .0 \\
\hline \multicolumn{5}{|l|}{ Clinical outcomes } \\
\hline Anticoagulation, n (\%) & $3(6.4)$ & $5(8)$ & $3(8)$ & .54 \\
\hline $\begin{array}{l}\text { Thromboembolism, } \\
\text { n (\%) }\end{array}$ & $0(0)$ & $2(3)$ & $1(3)$ & .42 \\
\hline Endocarditis, n (\%) & $1(2)$ & $1(2)$ & $0(0)$ & .71 \\
\hline \multicolumn{5}{|l|}{$\begin{array}{l}\text { Postop echocardiography } \\
\text { (last follow-up) }\end{array}$} \\
\hline LVEDD, cm (SD) & $5.21(1.1)$ & $4.95(0.81)$ & $4.67(0.6)$ & .07 \\
\hline LVESD, cm (SD) & 3.47 & 3.24 & 2.95 & .06 \\
\hline LVEF, \% (SD) & $72.4(13)$ & $71(12)$ & $72(11)$ & .89 \\
\hline $\begin{array}{l}\text { Transaortic gradient, } \\
\text { mm Hg (SD) }\end{array}$ & $24.8(23)$ & $21.4(16)$ & $14.7(9)$ & .31 \\
\hline LVM, g (SD) & $310(119)$ & $267(107)$ & $259(96)$ & .05 \\
\hline
\end{tabular}

$C A B G$, coronary artery bypass grafting; $S D$, standard deviation; $N Y H A$, New York Heart Association; $L V E D D$, left ventricular end-diastolic dimension; $L V E S D$, left ventricular end-systolic dimension; $L V E F$, left ventricular ejection fraction; $L V M$, left ventricular mass.

\section{Operative Details}

Operative and postoperative data are documented in Table 2. Allograft valves were implanted in $67(46 \%)$ patients. The Toronto Stentless Porcine Valve was implanted in the subcoronary position in $80(54 \%)$ patients. The bioprostheses were implanted using the subcoronary freehand technique in $130(88 \%)$. Seventeen $(12 \%)$ patients who had an allograft implanted received a freestanding root replacement with reimplantation of the coronary ostia. The mean valve size implanted was 24.6 (2.5) $\mathrm{mm}$ with no differences in size among the 3 LVM regression groups. There was no difference among groups in the frequency of concomitant coronary artery bypass grafting or mean number of bypass grafts performed per patient.

\section{Postoperative Echocardiography}

Postoperative echocardiographic details are listed in Table 2. There were significant trends of differences in LV end-diastolic diameter $(P=.07)$ and a trend for endsystolic dimensions among groups $(P=.06)$. Mean time 

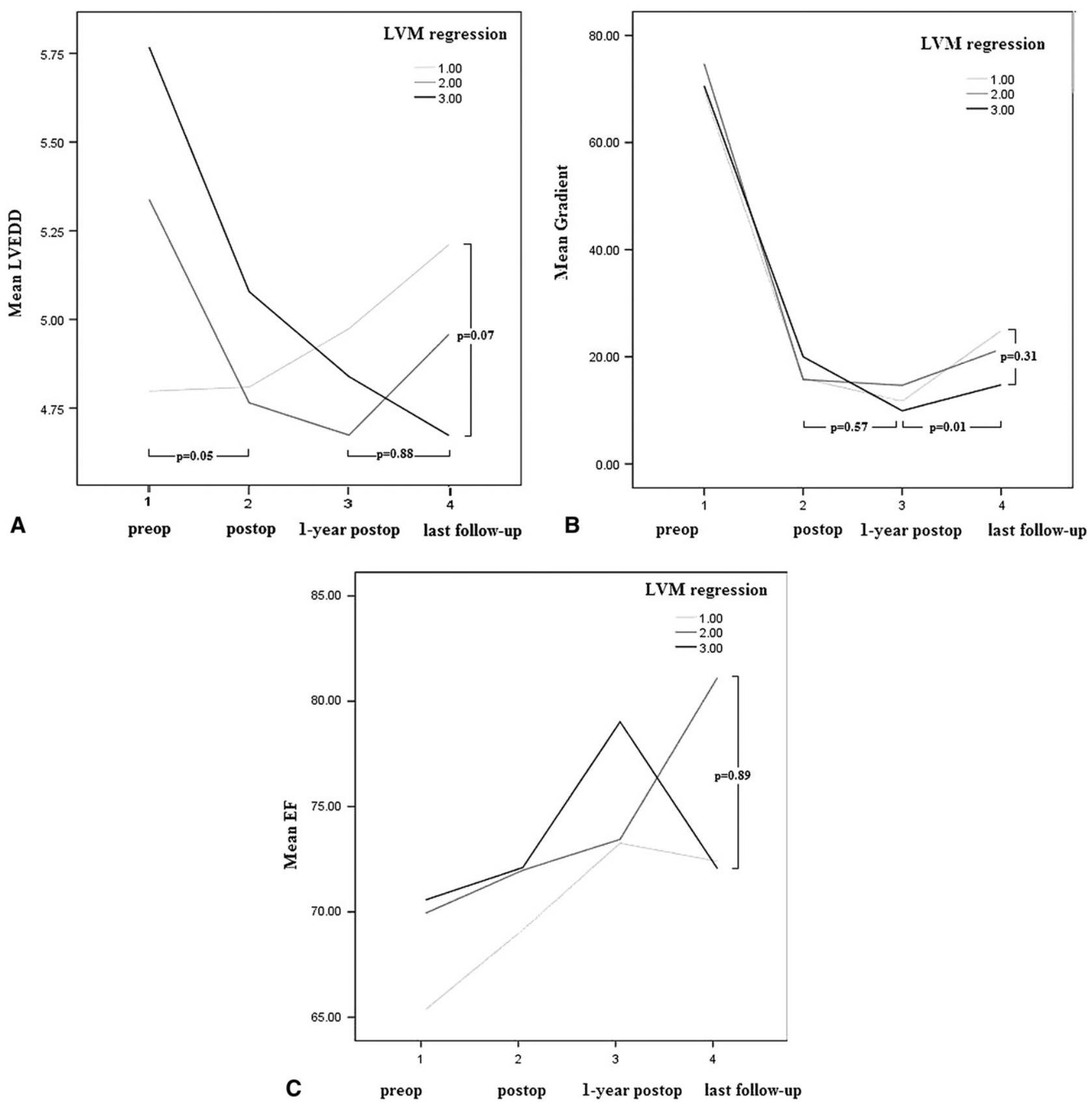

FIGURE 1. Changes in left ventricular end-diastolic diameter (LVEDD) (A), transvalvular gradient (B), and ejection fraction ( $E F)(\mathrm{C})$ during follow-up in patients groups with different degree of left ventricular mass ( $L V M)$ regression The $P$ value for the different LVM groups (vertical axis) has been calculated by analysis of covariance and the $P$ values for different time points (horizontal axis) are from the Bonferroni test.

to last echocardiogram was $6.2 \pm 3.2$ years. LVM at late follow-up was $310 \pm 119 \mathrm{~g}$ in group $1,267 \pm 107 \mathrm{~g}$ in group 2 , and $259 \pm 96 \mathrm{~g}$ in group $3(P=.05)$. Transvalvular gradients at follow-up were not significantly different among groups (group 1, $24.8 \pm 23 \mathrm{~mm} \mathrm{Hg}$; group 2, $21.4 \pm$ $16 \mathrm{~mm} \mathrm{Hg}$; group 3: $14.7 \pm 9 \mathrm{~mm} \mathrm{Hg} ; P=.31$ ). Two patients in group 1, 2 in group 2, and 1 in group 3 demonstrated an increased transvalvular gradient of more than $50 \mathrm{~mm} \mathrm{Hg}$, demonstrating degenerative disease of the replaced valve during follow-up. Changes in LV enddiastolic diameter, transvalvular gradients, and LV ejection fraction during follow-up for the 3 groups of patients are depicted in Figure 1. Patients in group 3 had smaller LV end-diastolic dimensions and lower postoperative transvalvular gradients, although this did not reach statistical significance. Between 1 year and late follow-up, there was a significant increase in transvalvular gradient in all groups $(P$ value from Bonferroni test, $P=.01)$. 


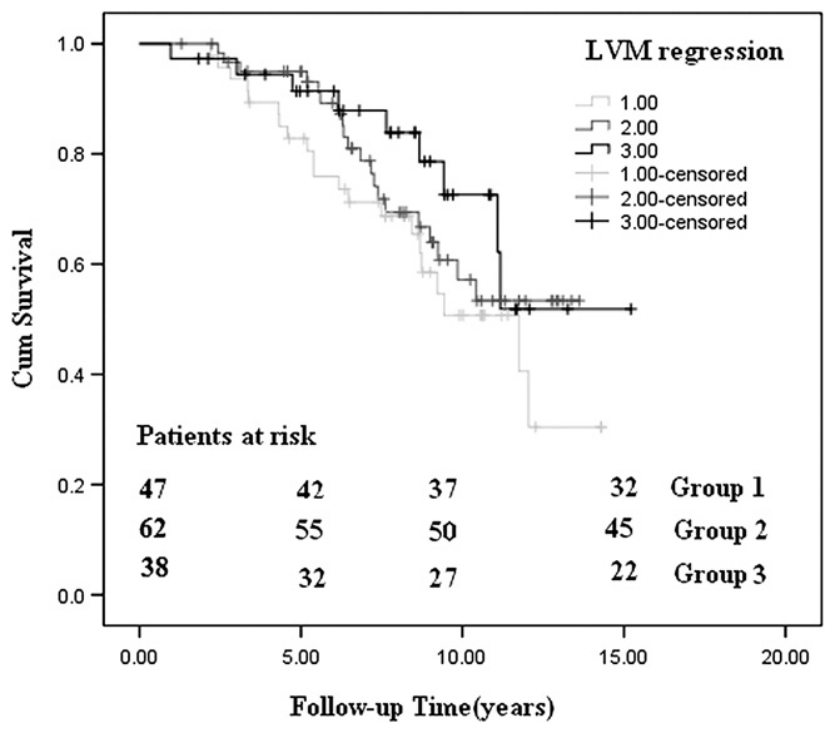

FIGURE 2. Actuarial survival according to left ventricular mass ( $L V M)$ reduction at 1 year of follow-up.

\section{Actuarial Survival}

The mean time to follow-up was 7.8 (3.1) years. Five-year (group 1, $89 \% \pm 5 \%$; group 2, 93\% $\pm 3 \%$; group 3, $94 \%$ $\pm 4 \%$ ) and 10 -year (group 1, $51 \% \pm 9 \%$; group 2, $54 \% \pm$ $8 \%$; group $3,72 \% \pm 10 \%$ ) actuarial survivals were not significantly greater in patients with enhanced LVM regression: $\log$-rank $=2.68 ; d f=2 ; P=.26$ (Figure 2).

\section{Cox Hazard Regression Analysis}

The results of univariable analysis are presented in Table 3. Cox proportional hazard survival regression analysis was undertaken to identify independent predictors of late mortality, and results are presented in Table 4. Independent predictors of late mortality were identified as the following: age 70 years or older $(P=.003)$, preoperative LVM $(P<.03)$, postoperative New York Heart Association class III/IV $(P<.001)$, and concomitant coronary artery bypass grafting $(P<.003)$. LVM regression greater than $150 \mathrm{~g}$ was independently protective against late mortality with a hazard ratio of $0.28(0.09-0.87)$

\section{DISCUSSION}

In this retrospective study we investigated whether superior LVM regression after AVR in patients with AS was associated with improved long-term survival. Through analysis of serial echocardiograms, we determined the extent of LVM regression after the first year of follow-up and assessed whether this had an association with late prognosis. Patients with enhanced LVM regression $(>150 \mathrm{~g})$ did not demonstrate improved survival on Kaplan-Meier analysis compared with those with less resolution of LVH. However, after adjustment for other confounders, multivariable Cox regression analysis demonstrated that the magnitude
TABLE 3. Predictors of late mortality in univariable analysis

\begin{tabular}{|c|c|}
\hline & $P$ value \\
\hline Age $\geq 70 y$ & $<.001$ \\
\hline Concomitant $\mathrm{CABG}$ & $<.001$ \\
\hline Sub-coronary technique & .005 \\
\hline Homograft valve & .01 \\
\hline Antihypertensive treatment (ACE inhibitor) & .03 \\
\hline Postop NYHA class III/IV & .03 \\
\hline Preop NYHA class III/IV & .05 \\
\hline Valve size $\geq 25 \mathrm{~mm}$ & .06 \\
\hline Preop LVM & .08 \\
\hline Emergency operation & .12 \\
\hline Hypertension & .21 \\
\hline $\mathrm{LVEF} \leq 30 \%$ & .23 \\
\hline Diabetes & .26 \\
\hline Redo AVR & .34 \\
\hline Serum creatinine $\geq 150 \mu \mathrm{mol} / \mathrm{L}$ & .50 \\
\hline Sex (male) & .59 \\
\hline Permanent pacemaker & .87 \\
\hline Hypercholesterolemia & .91 \\
\hline Loss of sinus rhythm & .93 \\
\hline
\end{tabular}

of LVM regression was an independent predictor of improved long-term survival.

Concentric LVH develops in patients with AS or systemic hypertension and represents adaptation of LV muscle to excessive intraventricular pressure. Such changes in the shape of the left ventricle allow it to maintain a normal relation between systolic wall stress and ejection fraction. Population studies have identified that LVH is associated with an

TABLE 4. Independent predictors of late mortality on multivariable analysis

\begin{tabular}{lcccc}
\hline & & \multicolumn{3}{c}{$\mathbf{9 5 . 0} \%$ CI for $\operatorname{Exp}(\mathbf{B})$} \\
\cline { 5 - 5 } & Sig. & $\operatorname{Exp}(\mathbf{B})$ & Lower & Upper \\
\hline Age $\geq 70$ y & .003 & 2.81 & 1.41 & 5.59 \\
Postop NYHA class III/IV & .000 & 62.84 & 12.10 & 326.24 \\
Concomitant CABG & .003 & 2.64 & 1.39 & 5.00 \\
Preop LVM & .036 & 1.00 & 1.000 & 1.01 \\
Preop NYHA class III/IV & .11 & 1.70 & 0.87 & 3.29 \\
Subcoronary implantation & .09 & 6.59 & 0.71 & 61.05 \\
Homograft valve & .24 & 0.60 & 0.25 & 1.410 \\
Serum creatinine $\geq 150 \mu \mathrm{mol} / \mathrm{L}$ & .25 & 2.48 & 0.52 & 11.81 \\
Antihypertensive treatment & .26 & 1.43 & 0.76 & 2.70 \\
$\quad$ & & & & \\
Emergency operation & .43 & 1.43 & 0.58 & 3.53 \\
Postoperative pacemaker & .64 & 1.29 & 0.42 & 3.97 \\
Valve size $\geq$ 25 mm & .84 & 0.92 & 0.42 & 1.99 \\
LVM $<$ 25 g (reference: group 1) & & 1.00 & & \\
LVM 25-150 g (group 2) & .19 & 0.61 & 0.294 & 1.286 \\
LVM $>$ 150 g (group 3) & .02 & 0.28 & 0.09 & 0.87 \\
\hline Sig. Sigibitor) & &
\end{tabular}

Sig., Significance; $\operatorname{Exp}(B)$, exponentiation of the B coefficient; $C I$, confidence interval; $N Y H A$, New York Heart Association; $C A B G$, coronary artery bypass grafting; $L V M$, left ventricular mass; $A C E$, angiotensin-converting enzyme. 
increased incidence of myocardial infarction, sudden death, and congestive heart failure. ${ }^{6,79}$ Accordingly, LVH is linked to impaired long-term survival compared with age-matched controls. ${ }^{7,8}$ Previous studies evaluating the impact of incomplete regression of ventricular hypertrophy on surgical outcome have been limited by small numbers of patients and a short duration of followup. $^{11,12}$ There are minimal data on the impact of persistent LVH on very long-term survival specifically after AVR in patients with AS. A lack of such information has led to extrapolations being made from the observational studies discussed herein. The consensus has been that residual LVH after AVR has a detrimental effect on long-term survival, ${ }^{5,13}$ although some investigators have reported contradictory findings. ${ }^{14}$ LVH in the setting of AS has been correlated with a number of adverse effects including abnormal coronary flow reserve and exacerbation of diastolic dysfunction. ${ }^{15,16}$ Consequently, cardiac surgeons and valve manufacturers have concentrated their efforts toward engineering prostheses with optimal hemodynamic performance to facilitate postoperative LVM regression.

$\mathrm{LVH}$ is the culmination of a variety of molecular processes in response to chronic pressure overload. It is associated with geometric chamber alterations, changes in ventricular mass, as well as myocardial cellular structure and development of fibrosis. ${ }^{17}$ Differences exist in the morphometry of hypertrophy associated with essential hypertension and AS. Strotmann and associates ${ }^{10}$ used strain-rate imaging studies of LV long- and short-axis function to demonstrate that despite similar degrees of LV wall thickness, AS and arterial hypertension had different effects on the rate of LV deformation. Consequently, the effect of LVH on outcomes in patients with hypertension cannot be justifiably applied to patients who have been surgically treated for aortic valve disease. In our study, we observed that superior LVM regression may have an independent effect on long-term survival after AVR for AS. We classified patients according to the degree of LVM regression that was observed at 1 year of followup. Forty-seven patients lost less than $25 \mathrm{~g}$ of their LV muscle mass; survival was poorest in this group, with a 10 -year actuarial survival of only $51 \% \pm 9 \%$. Interestingly, the LVM preoperatively was in fact lower than the follow-up value in this group (preoperative value $279 \mathrm{~g}$ vs postoperative value $310 \mathrm{~g}$ ), with this subset of patients demonstrating an increase in LVM. Sixty-two patients had regression of between 25 and $150 \mathrm{~g}$ over follow-up and 38 had a reduction of greater than $150 \mathrm{~g}$. Both of these patient groups were observed to have a net loss of LVM over the long term and had greater survival at 10 years: $54 \% \pm 8 \%$ and $72 \% \pm$ $10 \%$, respectively.

Numerous variables have been suggested to influence postoperative LVM regression. Recent studies have identified preoperative LVM as the most important determinant of postoperative LVM regression, ${ }^{18,19}$ with patients with a larger preoperative LVM demonstrating the greatest degree of LVM reduction. Other factors such as the type and size of valve implanted, hypertension, residual transaortic gradients, and the presence of ischemic heart disease are thought to have an impact on resolution of LVH. In accordance with these previous reports, preoperative LVM was higher in our study in the group of patients who demonstrated the greatest postoperative reduction in LVM. ${ }^{8,19}$ There were no significant differences between groups in the frequency of coexistent hypertension or the type and size of valve used. The need for concomitant coronary artery bypass grafting was not different between groups. Enhanced LVM regression was also associated with trends of significantly smaller LV enddiastolic dimensions and end-systolic diameter. This suggests that enhanced LVM regression may occur in association with improved LV remodeling after AVR. Transvalvular gradients were lower in group 3, and this may explain the presence of superior resolution of LVH in this group. This may validate the use of strategies aimed at optimizing valvular hemodynamics to promote LVM regression over the longer term. Reduced LVM regression may be secondary to a specific phenotype of LVH and may not necessarily be secondary to an inferior hemodynamic environment after AVR.

The reasons why LVM regression occurs in some individuals and is incomplete in others, despite similar preoperative values of LVM and postoperative hemodynamic and clinical profiles, is uncertain. The presence of increased amounts of myocardial fibrosis has been suggested as one possible factor responsible for this observation. ${ }^{20}$ The molecular basis of LVM regression after AVR is being elucidated. Walther and associates ${ }^{21}$ used an animal model to study the role of changes in the cardiac extracellular matrix. In a sheep model they observed that LVH induced by aortic banding was associated with a significant increase in extracellular matrix gene expression of matrix metalloproteinases and a number of their tissue inhibitors. Regression of these genes was noted after relief from chronic pressure overload in their model. ${ }^{21}$ Further investigation is necessary to scrutinize the molecular mechanisms responsible for postoperative LVM regression after AVR. In particular, efforts should be directed at understanding why some subsets of patients fail to demonstrate satisfactory LVM regression despite adequate relief of AS and whether specific clinical interventions in this group may be of value in promoting resolution of LVH.

The advent and subsequent evolution of surgical treatment for aortic valve disease has been accompanied by a progressive drive toward engineering prostheses with optimal hemodynamic performance. A major impetus behind these efforts has been the desire to facilitate remodeling of the left ventricle after AVR, principally through resolution of LVH. More recently, this has been invigorated by concerns regarding the generation of patient-prosthesis 
mismatch. Patient-prosthesis mismatch refers to circumstances in which a prosthesis is deemed to be too small for a given patient, resulting in a degree of residual impedance to transaortic flow This entity has been strongly linked with both morbidity and mortality in patients undergoing $\mathrm{AVR}^{5,22}$ One of the major concerns relating to patientprosthesis mismatch is that it predisposes to incomplete postoperative regression of $\mathrm{LVH} .{ }^{5}$ We have demonstrated that patients who have greater LVM regression after AVR may exhibit increased survival at very long-term followup. Furthermore, the group of patients who were observed to have the greatest LVM regression was also found to have lower postoperative tranvalvular gradients, although this did not reach statistical significance. A number of strategies can be used to avoid the development of patientprosthesis mismatch. The use of stentless valves, which are engineered to occupy the smallest possible area within the aortic root, is widely regarded as a means of maximizing the available cross-sectional area for transprosthetic flow. Procedures aimed at enlarging the aortic root represent an alternative method aimed at avoiding patient-prosthesis mismatch and maximizing the size of prosthesis that can be implanted. A number of randomized trials have been undertaken to compare performance of stentless valves with the presumably more hemodynamically "challenged" stented valve. The results have been conflicting, with some demonstrating improved hemodynamic performance and LVM regression after stentless $\mathrm{AVR},{ }^{23}$ while others have failed to identify any difference in such outcomes. ${ }^{24}$ One important conclusion that can be drawn from these studies is that both stented and stentless AVR can be undertaken with minimal morbidity and mortality. Similarly, concomitant aortic root enlargement procedures at the time of AVR can also be performed with a low risk to patients. ${ }^{25}$ Evidence that superior LVM regression is correlated with greater long-term survival warrants that interventions optimizing hemodynamic performance be used to promote resolution of LVH.

\section{CONCLUSIONS}

Enhanced LVM regression at late follow-up in patients undergoing AVR is associated with improved long-term survival. Strategies to optimize postoperative LVM regression should be considered in view of potential prognostic benefit.

\section{References}

1. Petereson KL, Ricci D, Tsuji J, Sasayama S, Ross J Jr. Evaluation of chamber and myocardial compliance in pressure overload hypertrophy. Eur J Cardiol. 1978; 7(Suppl):195-211.

2. Barrett-Boyes BG. Homograft aortic valve replacements in aortic incompetence and stenosis. Thorax. 1964;19:131-50.

3. Christakis GT, Joyner CD, Morgan CD, Fremes SE, Buth KJ, Sever JY, et al. Left ventricular mass regression early after aortic valve replacement. Ann Thorac Surg. 1996;62:1084-9.
4. Kuhl HP, Franke A, Puschmann D, Schondube FA, Hoffman R, Hanrath P. Regression of left ventricular mass one year after aortic valve replacement with mosaic bioprosthesis. J Heart Valve Dis. 2002;11:529-36.

5. Ruel M, Al-Faleh H, Kulik A, Chan KL, Mesana TG, Burwash JG. Prosthesispatient mismatch after aortic valve replacement predominantly affects patients with pre-existing left ventricular dysfunction: effect on survival, freedom from heart failure, and left ventricular mass regression. J Thorac Cardiovasc Surg. 2006;131:1036-44

6. Koren MJ, Devereux RB, Casae PN, Savage DD, Laragh JH. Relation of left ventricular mass and geometry to morbidity and mortality in uncomplicated essential hypertension. Ann Intern Med. 1991;114:345-52.

7. Levy D. Clinical significance of left ventricular hypertrophy: insights from the Framingham study. J Cardiovasc Pharmacol. 1991;17(Suppl 2):S1-6.

8. Kannel WB, Dannenberg AL, Levy D. Population implications of echocardiographic left ventricular hypertrophy. Am J Cardiol. 1987;60:85I-93.

9. Ghali JK, Liao Y, Simmons B, Castaner A, Cao G, Cooper RS. The prognostic role of left ventricular hypertrophy in patients with or without coronary artery disease. Ann Intern Med. 1992;117:831-6.

10. Strotmann JM, Lengenfelder B, Blondelot J, Voelker W, Hermann S, Ertl G, et al. Functional differences of left ventricular hypertrophy induced by either arterial hypertension or aortic valve stenosis. Am J Cardiol. 2008;101:1493-7.

11. Orsinelli DA, Aurigemma GP, Battista S, Krendel S, Gaasch WH. Left ventricular hypertrophy and mortality after aortic valve replacement for aortic stensois. A high risk subgroup identified by preoperative relative wall thickness. J Am Coll Cardiol. 1993;22:1679-83.

12. Tao K, Sakata R, Iguro Y, Ueno M, Tanaka Y, Otsuji Y, et al. Impact of valve prosthesis-patient mismatch on intermediate-term outcome and regression of left ventricular mass following aortic valve replacement with mechanical prosthesis. J Card Surg. 2007;22:486-92.

13. Fuster RG, Montero Argudo JA, Albarova OG, Sos FH, Lopez SC, Codoner MB, et al. Patient prosthesis mismatch in aortic valve replacement: really tolerable? Eur J Cardiothorac Surg. 2005;27:441-9.

14. Guadino M, Alessandrini F, Glieca F, Luciani N, Cellini C, Praglilola C, et al. Survival after aortic valve replacement for aortic stenosis: does left ventricular mass regression have a clinical correlate? Eur Heart J. 2005;26:51-7.

15. Bakhtiary F, Schiemann M, Dzemali O, Dogan S, Schachinger V, Ackermann $\mathrm{H}$, et al. Impact of patient-prosthesis mismatch and aortic valve design on coronary flow reserve after aortic valve replacement. J Am Coll Cardiol. 2007;49:790-6.

16. Hildick-Smith DJ, Shapiro LM. Coronary flow reserve improves after aortic valve replacement for aortic stenosis: an adenosine transthoracic echocardiography study. J Am Coll Cardiol. 2000;36:1889-96.

17. Swynghedauw B. Molecular mechanisms of myocardial remodling. Physiol Rev. 1999;79:215-61.

18. Lim E, Ali A, Theodorou P, Sousa I, Ashrafian H, Chamogeorgakis T, et al. Longtitudinal study of the profile and predictors of left ventricular mass regression after stentless aortic valve replacement. Ann Thorac Surg. 2008; 85:2026-9.

19. Hanayama N, Christakis GT, Mallidi HR, Rao V, Cohen G, Goldman BS, et al Determinants of incomplete left ventricular mass regression following aortic valve replacement for aortic stenosis. J Card Surg. 2005;20:307-13.

20. Krayenbuehl HP, Hess OM, Monrad ES, Schneider J, Mall G, Turina M. Left ven tricular myocardial structure in aortic valve disease before, intermediate, and late after aortic valve replacement. Circulation. 1989;79:744-55.

21. Walther T, Schubert A, Falk V, Binner C, Kanev A, Bleiziffer S, et al. Regression of left ventricular hypertrophy after surgical therapy for aortic stenosis is associated with extracellular matrix gene expression. Circulation. 2001;104(suppl I): I54-8.

22. Rao V, Jamieson WR, Ivanov J, Armstrong S, David TE. Prosthesis-patient mismatch affects survival after aortic valve replacement. Circulation. 2000;102(19 Suppl. 3):III5-9.

23. Walther T, Falk V, Langebartels G, Kruger M, Bernhardt U, Diegeler A, et al. Prospectively randomized evaluation of stentless versus conventional biologic aortic valves: impact on early regression of left ventricular hypertrophy. Circulation. 1999;100(19 Suppl):II78-83.

24. Ali A, Halstead JC, Cafferty F, Sharples L, Rose F, Coulden R, et al. Are stentless valves superior to modern stented valves? A prospective randomized trial Circulation. 2006;114(1 Suppl):I535-40.

25. Castro LJ, Arcidi JM Jr, Fisher AL, Gaudiani VA. Routine enlargement of the small aortic root: a preventive strategy to minimize mismatch. Ann Thorac Surg. 2002;74:31-6. 